\title{
ASPECTS OF CONNECTION SENSE MOTOR IN ROBOTICS
}

\author{
Majur Numar, Naja Vilajkat, Veikj Alanan \\ University of Mumbai \\ Mumbai, India
}

\begin{abstract}
In recent years research on aspects of sensorimotor connection in robotics is gaining development. This is due, in part, by cheapening the need to build hardware, and partly to the new industrial design of flexible plant, which requires the reconfiguration of the sequence of actions needed for a varied production, which in turn It requires ease of movement of the material between points on the factory. Solutions to this problem transporting material in "flexible" environments are several. The first place the machines close to each other, and arranged so that one or more robot arms can carry the pieces there between; this configuration, a particular case of cells called flexible manufacturing, it is only suitable for a limited number of machines. Another valid solution is the use of AGVs (usually denoted as AGV, Autonomous Guided Vehicles), which are turning for guidance to pre programmed external systems such as a rail, buried electrical cables creating a magnetic field.
\end{abstract}

Keywords: Connection sensorimotor, Robotics, Robot Arms, Self - Guided Vehicles, Magnetic Field, Autonomous Vehicles

\section{INTRODUCTION}

The experimental building (usually) small mobile robots in university laboratories and amateur level (Microbots) is giving rise to a type of research that addresses aspects of connection sensorimotor (the most fundamental aspect of Robotics) from a point of view different from previous approaches, which also entails a change of vision in the classical conception of artificial Intelligence, which deals with trying to build artificial life. [1]

There are quite significant differences between the industrial robot manipulators and mobile. For a robot manipulator is useful and able to evolve in 3D space, you must possess varying degrees of mobility (degrees of freedom), however, a mobile robot with only two degrees of freedom can make things quite interesting on a work surface. On the other hand, since the robot manipulators usually work in highly structured spaces (fixed and appropriate to the tasks to be developed), require a system much less sophisticated perception. [2], [3] 
Finally, the best solution would be to have autonomous vehicles (denoted as ALV, Autonomous Land Vehicles) moving from one point to another without external help (at least not all the time), which makes them capable of generic navigation in a given environment from high level commands; to the sequence of such orders is often called the mission plan. [4]

\section{THEORETICAL FOUNDATIONS}

Navigation is called to the set of methods and used to direct the course of a mobile robot as it traverses its environment techniques. It is assumed that an order should reach destination without getting lost and without crashing or fixed obstacles, or with other phones that may eventually appear on the road.

To make the most common navigation is to have a map, but not necessarily. Map is any kind of representation of the environment in memory of the robot. From a map, you can determine an appropriate path between two desired points, which will be more or less complex as has been the chosen representation. By RDial mo, we must follow that path, first map types that are commonly used. They are primarily based on sensory input, with two types [5], [6], [7], [8]:

- Maps marks on the ground (landmarks) are particular locations easily identifiable by the robot 's sensory system (some corner, a group of well visible objects or neon tubes, etc.) that act as relevant brands (landmarks). Are represented as nodes of a graph (which may have associated characteristics, to ensure unambiguous identification), which are joined by arcs typically they represent accessibility (if any arc between two nodes, the robot can move directly from one to another of landmarks that represent nodes). These arcs can also be labeled with characteristics as travel distance, direction, transit time, etc.

- Maps occupation: they are based on representing the ground as a grid, regular or not, each of whose cells contains a useful value for the robot, which is usually the certitude of occupation, ie what degree of belief has the robot on the status of a particular box, from -1 (safe which is free) to +1 (is sure is busy) through 0 (no evidence in any sense). These maps can be constructed by visual methods, by taking images for a stereo pair of cameras (or one that goes on the robot and placed in various positions), from projections of limit points of an object, as shown in the following figure: 
FIGURE 01

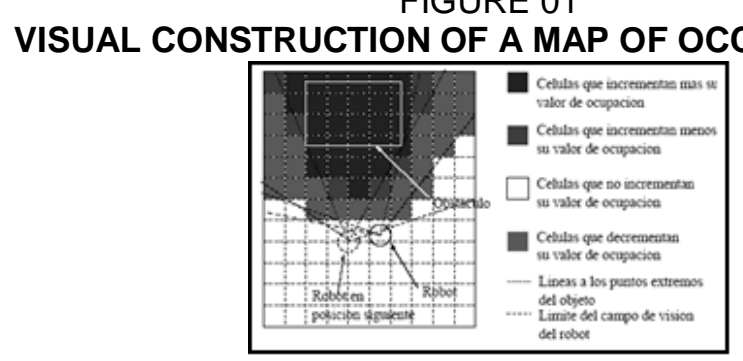

The maps can also be classified according to what they store:

- Maps of free space: as in maps, marks the storage structure chosen is also the graph, but this time each node represents a stopping point where the robot can stop to explore the environment through its sensors. The arches are straight lines that the robot can travel between these points without impediment; obviously will limit potential obstacles [10\}

\section{METHODOLOGY}

The study also fits the purposes of non - experimental, descriptive, where there have been raised hypothesis approach, but if you have defined a set of variables; as regards Hernandez, Fernandez and Baptista (2006, p. 205), "is to observe phenomena as given in the nat context ural, then analyze them . That is, existing situations are observed, not caused intentionally the investigator". Also, it is not intended to manipulate the variable under study, since in the case of the variable referring to social innovation will be seen in its natural context; then be analyzed without causing any change in them. [11], [12], [13], [14]

\section{RESEARCH RESULTS}

A mobile robot, as other types of robot may be considered essentially as a system (a collection of sensors, actuators, and computational elements) organized so that exhibit an intelligent response action successes stimuli. Such a system does not have to be complex. In fact, some of the simplest mobile robots respond to the following scheme. [15]

They consist of two motors that rotate respective wheels independently. Do not carry processor, all your hardware consists of the drivers of engine power, and two programmable counters start counting on receiving an external signal, and for the duration of your account, up to a preset generate a signal indicating the motor that moves in the opposite direction (B). The rest of the time each engine moves forward $(F)$. The counters are connected to sensors S1 and S2 shock, as shown in the following figure: 
FIGURE 02 . Time each engine moves forward $(F)[16]$

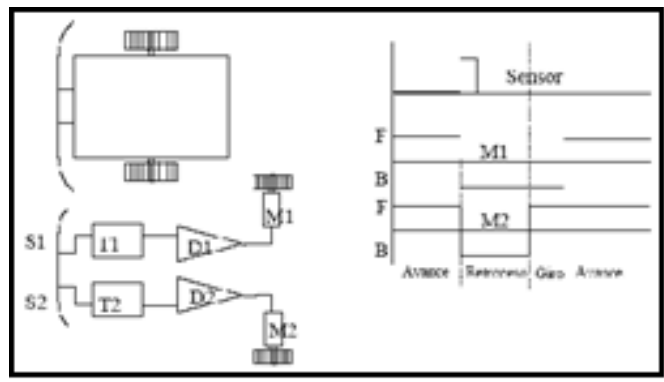

By moving both motors at the same speed and in the same direction $(F)$ the robot moves. When hitting an obstacle, both motors reverse their direction, and the robot back. But the counter of one of them is set to less than the other time, whereby the reversed both rotate in different direction for a moment, which makes the robot to turn around its own axis, thus it is possible that no longer point to the obstacle.[17], [19].

\section{FINAL THOUGHTS}

If, in addition, one of the engines was made to rotate a bit slower in the direction $\mathrm{B}$, the robot would have to fall back in an arc. This would follow approximately the walls, as shown in the right pane of the previous figure. In that case, the outside observer would assign a purpose robot, when in fact the "program" does not explicitly set. In fact, you can even say that there is a program in the traditional sense: all this can be implemented with analog circuitry, even better to do it digitally, whenever the spirit of simplicity is preserved.

This example serves to illustrate a direct, low - level connection between perception and action, but this is not the only way. It can also be (using more sophisticated sensors) trying to locate known external physical aspects by the pre - stored map, make a planning way before seen by the media, and follow it using landmakrs or odometry.

\section{REFERENCES}

[1]. Corke, Peter I. Robotics, Vision and Control: Fundamental algorithms in Matlab. 1st ed. New York: Springer, 2011. ISBN 9783642201431.

[2]. Siegwart, Roland; Nourbakhsh, Illah Reza; Scaramuzza, Davide. Introduction to autonomous mobile robots [online]. 2nd ed.

[3]. Cambridge: MIT ress, P cop. 2011 [Accessed: 10/09/2016] Available.: <http://site.ebrary.com/lib/upcatalunya/docDetail.action?docID=10453037>. ISBN 9780262015356 .

[4]. Ollero Baturone, Hannibal. Robotics: manipulators and mobile robots. Barcelona: Marcombo Boixareu, cop. 2001. ISBN 8426713130

[5]. Bierly, N., SCOTT, H., TUNER, H. Lanz, J. (2000). The historical context of the evolution of information technologies. Editorial Review. Madrid Spain.

[6]. WAX, L. (2010). Using cutting - edge technologies in the world. Ed itorial Vid. Barcelona, Spain.

CROW, J. (2009). Disruptive technologies in the university integrative field. Mac Graw Hill, Madrid.

[7]. Amelec, V. (2015). Methodology to increase the adaptability and flexibility of the supply chain of automotive company through lean manufacturing.Advanced Science Letters, 21(5), 1517-1520.

[8]. Viloria, A., Vasquez, C., \& Nunez, M. (2009, January). Use of the data envolvent analysis to determine the correct management of the economic resources of a country. In Adaptive Science \& Technology, 2009. ICAST 2009. 2nd International Conference on (pp. 422-425). IEEE.

[9]. Viloria, A., Urbina, M. C., Rodríguez, L. G., \& Muñoz, A. P. (2016). Predicting of Behavior of Escherichia Coli Resistance to Imipenem and Meropenem, using a Simple Mathematical Model Regression. Indian Journal of Science and Technology, 9(46).

[10]. Amelec, V., \& Alexander, P. (2015). Improvements in the Automatic Distribution Process of Finished Product for Pet Food Category in Multinational Company. Advanced Science Letters, 21(5), 1419-1421.

[11]. Viloria, A., \& Robayo, P. V. (2016). Virtual Network Level of Application Composed IP Networks Connected with Systems-(NETS Peer-to-Peer). Indian Journal of Science and Technology, 9(46). 
[12]. Viloria, A., \& Moros, M. A. (2016). Implantation System Brine Recover from Some Chemical Treatment Tanks in a Plant Chlor-Alkali. Indian Journal of Science and Technology, 9(46).

[13]. Viloria, A., Vasquez, C., \& Nuñez, M. (2009). Propuesta de un mecanismo de medición de las variables que afectan la eficie ncia de las instituciones públicas encargadas de generar bienestar social: caso Venezuela. Universidad Ciencia y Tecnología, 13(52).

[14]. Viloria, A. (2007). Modelos socioeconómicos para las pymes. Universidad, Ciencia y Tecnología (UCT), 11(42), 39-44.

[15]. Torres, M., Vasquez, C., \& Viloria, A. (2010). Gestión y calidad de la información en el gobierno electrónico. Universidad Ciencia y Tecnología, 14(54)

[16]. Viloria, A. (2012). INDICADORES DE GESTIÓN DE LOS PROGRAMAS DE MICROCRÉDITOS. REDIP-Revista Digital de Investigación y Postgrado, 1(3).

[17]. Amelec, V. (2015). Validation process container for distribution of articles for home. Advanced Science Letters, 21(5), 1413-1415.

[18]. Amelec, V. (2015). Validation of strategies to reduce exhausted shelf products in a pharmaceutical chain. Advanced Science Letters, 21(5), $1403-1405$.

[19]. Amelec, V., \& Carmen, V. (2015). Design of a model of evaluation of productivity for microfinance institutions. Advanced Science Letters, 21(5), 1529-1533. 
